Review

\title{
Psilocybin as a Novel Pharmacotherapy for Treatment-Refractory Anorexia Nervosa
}

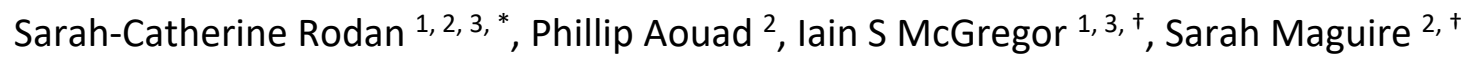

1. Lambert Initiative for Cannabinoid Therapeutics, Brain and Mind Centre, The University of Sydney, Australia; E-Mails: sarah-catherine.rodan@sydney.edu.au; iain.mcgregor@sydney.edu.au

2. InsideOut Institute for Eating Disorders, The Boden Collaboration for Obesity, Nutrition, Exercise and Eating Disorders, The University of Sydney, Australia; E-Mails: phillip.aouad@sydney.edu.au; sarah.maguire@sydney.edu.au

3. School of Psychology, Faculty of Science, The University of Sydney, Australia

+ Contributed equally as senior authors

* Correspondence: Sarah-Catherine Rodan; E-Mail: sarah-catherine.rodan@sydney.edu.au

Academic Editor: Sarah Maguire

Special Issue: Neurobiological Underpinnings of Anorexia Nervosa

OBM Neurobiology

2021, volume 5 , issue 2

doi:10.21926/obm.neurobiol.2102102
Received: April 08, 2021

Accepted: June 15, 2021

Published: June 24, 2021

\begin{abstract}
Anorexia Nervosa (AN) is a major health problem with one of the highest mortalities and treatment costs of any psychiatric condition. Cognitive behavioural therapy (CBT) is currently the most widely used treatment for $A N$ in adults but provides remission rates $\leq 50 \%$. Treatment drop-out is exceedingly high and those that persevere with treatment often relapse, causing increased risk of morbidity and mortality. There is an urgent need to find new interventions, especially as there are no approved pharmacological treatments for AN. Ideally, new treatments would target treatment-resistance and to decrease the chronicity associated with the disorder. Over the past two decades, emerging research into classic psychedelic substances (lysergic diethylamide acid (LSD), 5-Methoxy-N,N-Dimethyltryptamine (5-MeO-
\end{abstract}

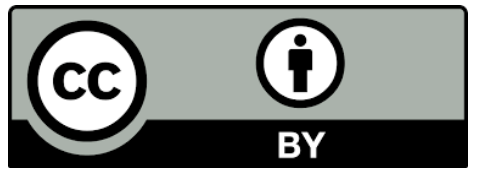

(C) 2021 by the author. This is an open access article distributed under the conditions of the Creative Commons by Attribution License, which permits unrestricted use, distribution, and reproduction in any medium or format, provided the original work is correctly cited. 
DMT), N,N-Dimethyltryptamine (DMT) and psilocybin), indicates that marked reductions in anxiety and depression-like symptoms, and lasting improvement in mental health, can follow from one or two exposures to these psychedelic substances. Anxiety and depression are the most prevalent co-morbid psychiatric symptoms in AN. Here we suggest that classic psychedelics, particularly psilocybin, have the potential to normalise dysfunctional neurobiological systems in AN and provide a novel treatment intervention that is worthy of consideration, particularly for treatment-resistant patients.

\section{Keywords}

Anorexia nervosa; treatment-resistant; psilocybin; anxiety; depression; cognitive flexibility; serotonin; psychotherapy

\section{The History and Resurgence of Classic Psychedelics in Medicine}

Classic psychedelics are a subset of hallucinogenic drugs that have historically been used to induce altered states of consciousness. Pharmacologically, they share the property of having agonist (or partial agonist) effects on the serotonin (5-hydroxytryptamine (5-HT)) $5 \mathrm{HT}_{2}$ receptor. Classic psychedelics include the tryptamine derivatives (lysergic diethylamide acid (LSD); N,NDimethyltryptamine (DMT, the active ingredient in the ayahuasca brew); 5-Methoxy-N,NDimethyltryptamine (5-MeO-DMT) and psilocybin) and the phenethylamine derivative, mescaline. Psilocybin and mescaline have been used as sacraments since ancient times dating back to $8600 \mathrm{BC}$ $[1,2]$. Shamanic ceremonial use of psilocybin, mescaline, 5-MeO-DMT and ayahuasca remain documented today among many indigenous groups through South-Central America [1, 3, 4].

Scientific landmarks over the past few decades involving classic psychedelic drugs include the following:

1950s-1966: Psychedelics were first investigated for treatment of mental health problems and approximately 2000 clinical papers were published on LSD, psilocybin and mescaline [5]. However political concerns over widespread recreational use led to imposition of regulatory obstacles and a hiatus in research for 24 years.

1990s: Dr. Rick Strassman began conducting human research on DMT. A case study described a 34-year-old man finding relief from his obsessive-compulsive symptoms after ingesting psilocybincontaining mushrooms $[5,6]$.

2006-2008: Moreno and Delgado reported that psilocybin is well-tolerated and induces impressive reductions in symptoms in patients with refractory obsessive-compulsive disorder (OCD). Johns Hopkins University described positive effects in the treatment of personality disorder, maintained at 14-month follow-up [7, 8].

2010-Present: The past decade has seen a significant surge in interest on the use of classic psychedelics, particular LSD and psilocybin, in treatment-refractory mental health conditions. Efficacy has been demonstrated in (mostly small) studies of depression, anxiety disorders and substance misuse. In 2014 the first doctor is legally authorised to administer LSD-assisted grouptherapy to patients in Switzerland [9]. 
Recent clinical trials have mostly focused on psilocybin due to its shorter duration of action (4-6 h) compared to LSD (8-12 h) and its lower potency than LSD. In addition, LSD accrued an unfortunate and arguably undeserved reputation in the 1960s for causing prolonged psychosis in recreational users. Cohen (1960) reported a $0.08 \%$ risk of a psychotic reaction lasting more than 48 hours, although he stated that "in the clinical setting LSD is overwhelmingly safe and effective" [5].

Psilocybin is considered the classic psychedelic with the least risk of adverse events with no risk of prolonged psychosis in a clinical setting $[10,11]$. It has recently gained FDA designation as a "breakthrough therapy" for both treatment-resistant depression (TRD) and major depressive disorder (MDD). Emerging evidence of significant benefits for mental health has supported decriminalisation and legalisation for therapeutic use in Oregon, United States (November 2020). Of all the classic psychedelics, psilocybin is likely to have the greatest potential for international approval as a therapeutic agent.

This review will therefore primarily focus on the medical use and therapeutic potential of psilocybin in treating anorexia nervosa (AN). This is not to deny the positive therapeutic effects obtained with LSD [12, 13], 5-MeO-DMT [14-16] and DMT/ayahuasca [17] and likely common benefits within this group of pharmacologically-similar hallucinogens.

\section{The Effects of Psilocybin}

Psilocybin (4-phosphoryloxy-N,N-dimethyltryptamine) is a psychoactive alkaloid present in more than 100 mushroom species worldwide. It was first isolated from Mexican mushrooms in 1959 by Albert Hofmann [18], the same chemist who had previously discovered the psychedelic properties of LSD in 1943 [19]. As with LSD, the Sandoz drug company, Hofmann's employer, marketed and distributed purified psilocybin as an experimental therapeutic drug to be used by psychiatrists in assisting their patients. LSD has approximately 100 -fold greater potency than psilocybin in terms of effective doses (e.g. 100-200 $\mu$ g versus 15-30 mg typical doses) [19].

Psilocybin is metabolised in vivo through dephosphorylation to the active metabolite psilocin (4hydroxy-dimethyltryptamine) (Figure 1) [20]. Psilocin has significant affinity for the serotonin receptors $5-\mathrm{HT}_{2 \mathrm{~A}}, 5-\mathrm{HT}_{2 \mathrm{C}}$ and $5-\mathrm{HT}_{1 \mathrm{~A}}[19,21]$. Following oral administration, the onset of psychoactive effects begins at 20-40 minutes, with peak effects experienced after 60-90 minutes and an overall duration of 4-6 hours [22].

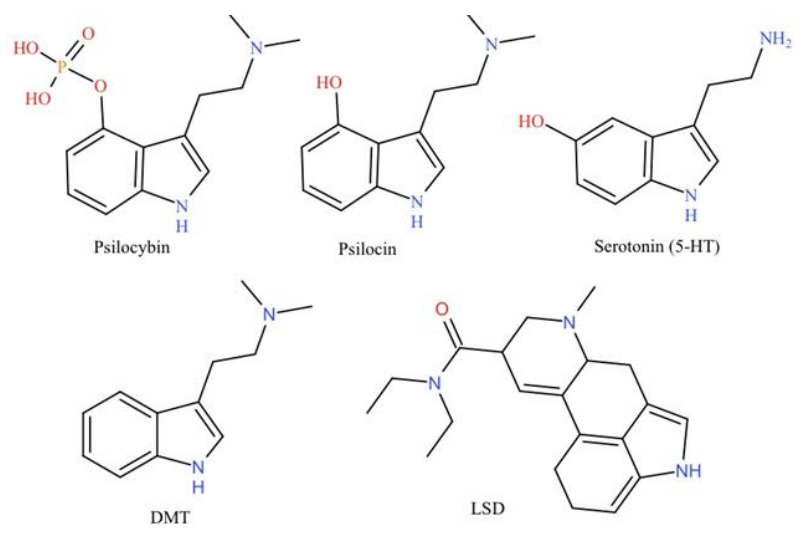

Figure 1 Chemical structure of psilocybin, psilocin, the neurotransmitter serotonin, DMT and LSD. All molecules belong to the tryptamine family, defined by an indole (fused benzene and pyrrole ring and a 2-aminoethyl group at the third carbon). 
There have been numerous laboratory studies involving the controlled administration of psilocybin to human volunteers. A recent review of some such studies [23] characterises low to high doses of psilocybin as involving a range from $2 \mathrm{mg}$ (low) to $28 \mathrm{mg}$ (high). Other studies have used doses up to $0.6 \mathrm{mg} / \mathrm{kg}$ psilocybin (i.e. $45 \mathrm{mg}$ to a person who weighs $75 \mathrm{~kg}$ ) [24, 25].

Acutely, psilocybin increases spirituality $[7,8,26-28]$, emotional empathy $[29,30]$, creative thinking [30, 31], optimism, happiness, mindfulness [32], insightfulness [33], motivation [34], memory recovery [35], acceptance of, and connectedness to, others [35, 36], and induces ego dissolution/personality change (i.e. collapse of rigidified identity) [37] and emotional breakthrough experiences [38].

The emotional breakthroughs during the acute psilocybin experience may be therapeutically relevant to the treatment of refractory clinical conditions such as TRD [34]. Participants report increased open-mindedness and psychological/cognitive flexibility, readiness to try and engage in new activities and improved ability to dismantle rigid habitual mental templates [34]. This can result in long-term salutary effects on mental health. Enhancements in emotional empathy, openness and connectedness may increase trust between patient and therapist giving psilocybin therapeutic utility as an adjunct during psychotherapy sessions. Notably, such openness in the therapeutic setting appears to be a tremendous challenge for many individuals with AN.

The phenomenon of a "bad trip" or "psychedelic crisis" is part of psychedelic folklore and described by many writers, and in case reports and clinical studies [39, 40]. This refers to overwhelming and often terrifying experiences that individuals can sometimes experience on classic psychedelics, including LSD and psilocybin [41]. In a recent survey of nearly 2000 people having "challenging experiences" with psilocybin (i.e. a "bad trip") during illicit use, $11 \%$ noted that the experience occurred in a context that put themselves or others at risk [41]. A year later, 7.6\% had sought treatment for enduring psychological symptoms arising from the experience [41]. This underscores the imperative that therapeutic interventions involving psilocybin should best occur in a carefully controlled environment with medical assistance at hand.

This review will argue that psilocybin is safe to use in individuals with severe and refractory psychiatric conditions when under careful medical supervision and has the potential to provide a dramatic alleviation of complex psychological symptoms in a way that might provide a much-needed therapeutic breakthrough in AN.

\section{Anorexia Nervosa}

Eating disorders (ED) such as anorexia nervosa (AN), bulimia nervosa and binge eating disorder affect over $9 \%$ of the population worldwide, predominantly women [42]. According to the Diagnostic and Statistical Manual of Mental Disorders [43], AN is characterised by a severe pathological fear and anxiety around food, food intake, and body weight. People with AN regularly engage in persistent ritualistic behaviours to restrict energy intake and therefore prevent weight gain [43]. Evidence also suggests abnormalities in reward systems, however the relevance to symptoms in AN and perpetuation of the illness remains unsure [44]. Such behaviours interfere with the healthy physiological function of the individual, further perpetuating chronic food refusal and deprivation, often leading to devastating physical symptoms.

Along with substance use disorders, AN has the highest treatment costs and mortality of any psychiatric illness [45]. It has a standardised mortality ratio of 5.86 [46], with mortality arising from 
malnutrition and suicide. A large proportion of patients develop severe and enduring AN (>7 years) [47], around $30 \%$ have an illness duration greater than 15 years, and only $31 \%$ reach recovery after 9 years [48]. Approximately $2-4 \%$ individuals with AN do not recover and experience life-long persistence of the illness [48]. AN in adulthood is considered one of the most difficult psychiatric conditions to manage and treat [49].

\section{Treatment Approaches for AN}

There have been very few recent advances in the effective treatment of AN. Attempts to challenge the underlying psychopathology of eating disorders can often be highly distressing and confronting for individuals with AN. As treatment progresses, a greater intensity of fear and anxiety around weight gain can develop that contributes to high relapse rates [50,51]. Although increases in body mass index (BMI) can often be noted at the end of treatment, up to $50 \%$ of patients relapse, or prematurely drop-out from treatment. This underscores the challenges faced by therapists in trying to implement lasting change in patients with AN.

Motivation to change, which is sorely lacking in individuals with refractory $A N$, is an important predictor of treatment response [52] and relapse prevention [53]. Increasing and maintaining motivation to recover throughout treatment contributes to positive long-term outcomes. Emotional avoidance and denial/lack of insight of illness and its severity is highly common during the acute phases of the illness and contributes significantly to treatment-resistance [54]. Current psychotherapies appear to often lack the power to effectively target and change such rigidified belief symptoms.

\subsection{Cognitive Behavioural Therapies}

Cognitive behavioural therapy (CBT) is the most widely used treatment for adults with eating disorders. CBT involves identifying and challenging distorted cognitions, maladaptive patterns, as well as reducing negative emotions and feelings about food, eating, body shape and weight to induce weight gain and weight restoration [55].

A multitude of modified CBT and psychotherapy programs have been developed including CBTAN [55], CBT-E [56], MANTRA and SSCM [57]. However, remission rates are often low, typically between $17-50 \%$ [51, 55, 58-60] with drop-out rates high, up to 50\% [59]. Given the modest efficacy of CBT for treating AN in adults there is clearly an urgent need to improve upon currently available therapies.

\subsection{Pharmacological Interventions}

There are no currently available pharmacological treatment options with demonstrated efficacy in remitting AN. Available pharmacological treatments are generally inadequate and some are associated with significant safety concerns [61]. Trials of various atypical antipsychotics (e.g. aripiprazole $[62,63]$ and olanzapine [64, 65]) and antidepressants (e.g. sertraline [66], citalopram [67], fluoxetine [68,69], mirtazapine [66], bupropion [61]) have demonstrated only limited efficacy in increasing BMI, stabilising weight, or reducing anxious, depressive and obsessive-compulsive symptoms $[70,71]$. 
Novel approaches that have been trialled include the use of the neuropeptide oxytocin [72, 73] which can modulate food consumption, social cognition, and anxiety [72, 73]. There was no evidence, however, of significant weight gain in AN following intranasal oxytocin, although it may reduce the stress response in anticipation of food [73] and attenuate attentional vigilance to food, eating and body shape [72].

The main psychoactive constituent of cannabis ( $\Delta^{9}$-tetrahydrocannabinol (THC)) has welldocumented appetite stimulatory effects and a range of potential medical applications [74]. In a randomized controlled trial, pharmaceutical THC capsules (Dronabinol) administered over four weeks produced a greater increase in average weight in AN patients $(0.73 \mathrm{~kg})$ than placebo in combination with standard psychotherapy [61, 75].

Psychedelic-assisted psychotherapy is of significant interest as a novel intervention for AN although evidence is highly preliminary at present. Renelli and colleagues reported qualitative evidence of reduction or cessation of eating disorder (ED) and co-morbid symptoms following consumption of ayahuasca. Individuals quote the experience as a "bottom-up approach that is very much really rewiring things" and "I think it's just a deeper recovery. It just goes deeper, it gets to the root of why it developed in the first place" [76].

John Hopkins University (NCT04052568), Imperial College London (NCT04505189) and the University of California (NCT04661514) have received approval to conduct phase 1 open-label clinical trials for psilocybin treatment of AN (results pending). These trials are supported by the aforementioned observations that psychedelics can increase motivation, insightfulness [33] and decrease emotional avoidance [35], all important predictors of treatment response in AN.

\section{Psilocybin Effects in Psychiatric Conditions Co-Morbid with AN}

AN frequently appears alongside psychiatric conditions such as anxiety and depressive disorders, substance use disorder (SUD), post-traumatic stress disorder (PTSD), and autism spectrum disorder (ASD). These co-morbidities, particularly anxiety disorders, contribute to the overall psychopathology of AN, exacerbating treatment-resistance, chronicity and mortality. The current literature on psilocybin therapy documents a spectrum of trans-diagnostic effects, with preliminary supportive evidence across a wide range of psychiatric disorders, asserting potential for treating an illness with a variety of co-morbidities such as AN.

\subsection{Anxiety Disorders}

Anxiety contributes significantly to the psychopathology of AN with pathological anxiety a major barrier to weight gain. Indeed, some believe AN is best classed as an anxiety disorder [77, 78]. The most common co-morbid anxiety disorders in AN are OCD and social phobia, which carry cooccurring estimates as high as 69\%-88.2\% [79-84]. Anxious avoidance and obsession with food, weight gain and eating are fundamental drivers of illness and the features most often associated with treatment resistance [78]. Severity of anxiety and anxious phenotypes predict greater illness morbidity and often differentiate patients who remit from those who do not $[85,86]$. Furthermore, childhood anxiety predicts increased caloric restriction, greater ED psychopathology and a lower $\mathrm{BMI}$ during acute phases of the illness $[87,88]$. 
In 9 patients with refractory OCD, Moreno et al. (2006) reported reductions of $23-100 \%$ of obsessive-compulsive symptoms following psilocybin [89] that lasted far beyond the short pharmacological half-life of the drug itself. Two small-scale, double-blind, placebo-controlled clinical trials are now ongoing in the United States to further evaluate psilocybin effects in OCD patients at the University of Arizona (NCT03300947) and Yale University (NCT03356483).

Anxiolytic effects by psilocybin have also been demonstrated in individuals with a lifethreatening cancer diagnosis. Ross et al. (2016) reported an immediate and lasting anxiolytic response in 29 individuals. At 6.5-month follow up 60-80\% of participants continued to meet criteria for clinically significant anxiolytic responses. Fifteen participants agreed to participate in a 4.5 year follow up and $70-80 \%$ continued to meet criteria for a significant anxiolytic response at that timepoint [28]. Grob et al. (2011) demonstrated significant anxiolytic responses in 12 subjects with advanced cancer at 1 and 3-months post-psilocybin [90]. Similarly, Griffiths et al. (2016) reported clinically significant anxiolytic effects in 51 cancer patients in a randomised, double-blind, cross-over trial. At 6-months follow-up $83 \%$ maintained clinically significant anxiolytic responses and $57 \%$ were in remission [91].

The evidence that psilocybin induces lasting amelioration of anxiety symptoms may hold particular promise in the treatment of AN. Decreasing the anxious avoidance of food-related stimuli and weight gain will likely assist the individual throughout treatment and long-term recovery.

\subsection{Fear, Trauma and PTSD}

The anxiety and fear seen in AN towards food and body weight gain has been further elucidated in neuroimaging studies. These portray activation of fear-related circuits by food-related stimuli, including the amygdala, in AN patients relative to healthy controls [92]. Intense fear is a key component in PTSD, an anxiety disorder that onsets following traumatic experiences. There are higher rates of PTSD in individuals with AN than the general population, with prevalence rates variously estimated at $10 \%$ [93], $13.7 \%$ [94] and $23.1 \%$ [95]. Trauma is known to be a risk factor in the development of eating-related psychopathology, most often sexually-related traumas that are present prior to onset of AN [94].

Functional magnetic resonance imaging ( $\mathrm{fMRI}$ ) studies indicate that psilocybin reduces neuronal activity in the amygdala and hippocampus, regions that process fear and threat-related stimuli and that interface with the prefrontal cortex during emotional processing of negative facial expressions [96-98]. Such effects are also reported in studies of evoked potentials using electroencephalogram (EEG) recordings $[99,100]$.

Modulation of the neural response to fear-inducing stimuli by psilocybin is also seen in preclinical models. Mice injected with low doses of psilocybin exhibited facilitated extinction of classically conditioned fear responses [101]. This provides presumptive evidence that psilocybin might facilitate the extinction of trauma-related cues and memories in humans.

Significant reductions in PTSD symptoms were obtained with the classic psychedelic 5-MeO-DMT when administered to U.S. Special Operations Forces Veterans diagnosed with trauma-related psychological and cognitive impairment [14]. An increase in psychological flexibility measured by The Acceptance and Action Questionnaire II (AAQ-II) was strongly associated with reductions of PTSD symptoms in these patients [14]. 
Helping AN patients to process the traumatic memories that contribute to AN onset, as well as their extreme fear associated with food and weight gain, would clearly be of long-term benefit. Emotional detachment and inability to re-experience trauma memories may benefit from the increase in emotional empathy [30] and memory consolidation effects induced by psilocybin [35, 36].

\subsection{Depressive Disorders, Suicidal Ideation and Suicide}

Major depressive disorder (MDD) is often co-morbid with AN with a lifetime prevalence of 50$75 \%$ of individuals with AN [102]. Suicide is a leading cause of mortality in AN [102] with patients having an 18.1 times higher risk of dying from suicide than the general population [45]. Approximately $80 \%$ of individuals with AN who attempted suicide reported that their worst suicide attempt occurred during an episode of $\operatorname{MDD}[102,103]$. Suicidal ideation and severe depression contribute to high rates of relapse during treatment [102].

Psilocybin produces remarkably rapid and sustained antidepressant effects in both MDD and TRD. An open-label feasibility study examined psilocybin effects in 12 patients with TRD [104]. At 1week post exposure, 67\% experienced clinically significant antidepressant effects and $58 \%$ met criteria for complete remission. At 3 months, antidepressant effects were maintained and $42 \%$ were still in remission. Patient reports noted "The reset switch had been pressed so everything could run properly; I felt my brain was rebooted; I had the mental agility to overcome problems". At 6 months follow-up [105] six patients reported continued significant improvements - "It was a change of state, to be stuck in that place of rumination and to be able to move out. It reconfigures you somehow." [35]. Another open label study of twenty participants with TRD found that $47 \%(n=9)$ maintained clinically significant antidepressant responses at 5 weeks post-psilocybin [106].

In participants with MDD, Davis et al. (2020) reported clinically significant reductions in depression. At 1-week post exposure 67\% experienced clinically significant antidepressant effects and $58 \%$ were in remission. At 4-weeks $71 \%$ maintained antidepressant effects and $54 \%$ maintained remission [106]. Very recently, Carhart-Harris et al. (2021) conducted a randomized, controlled trial, comparing psilocybin with the standard antidepressant escitalopram in 57 patients with MDD. Results showed that just 2 doses of psilocybin were just as effective as a 6-week course of escitalopram. A clinically significant antidepressant effect was reported in $70 \%$ of those allocated in the psilocybin group, compared to $47 \%$ with escitalopram and remission occurred in $57 \%$ and $28 \%$, participants respectively [107].

Significant long-term reductions in depressive symptoms have additionally been reported in patients with a life-threatening terminal disease diagnosis $[91,108]$. Significant and large reductions in suicidal ideation and depression have also been reported with 5-MeO-DMT treatment for traumarelated psychological and cognitive impairment [14].

Spirituality appears to protect against suicidal ideation $[109,110]$ and increased spirituality may be one mechanism through which psilocybin acts to improve mood and reduce suicidality [7]. Hendricks and colleagues, in a population study, reported that psychedelic use was associated with reduced suicidal ideation, psychological distress and past year suicide attempts [111]. Similarly, Carhart-Harris et al. (2018) reported reduced suicidal ideation at 6 months follow-up in TRD patients treated with psilocybin [105]. Zeifman et al. (2020) found that individuals with mild to very severe depression had significant reductions in suicidal ideation 4 weeks following psilocybin [36]. 
Six clinical trials involving psilocybin treatment in depressive disorders are currently ongoing in the United States, United Kingdom and Europe (NCT03866174; NCT03429075; NCT03715127; NCT03181529; NCT03554174; NCT03380442).

The promising evidence of psilocybin's therapeutic use in depressive disorders, as well as comparable, if not superior, efficacy compared to standard antidepressants, indicates the potential of psilocybin to ameliorate one of the most prevalent co-morbidities seen in AN, namely depression, and to protect against suicidality.

\subsection{Addiction and Substance Use Disorders}

The compulsive self-starvation seen in AN that persists despite obvious self-harm, and the strong resistance to recovery, are characteristics that are somewhat reminiscent of addictions and substance use disorders (SUDs). In animal models, food deprivation increases the reinforcing effects of drugs of abuse (e.g. cocaine, opioids) suggesting commonality of mechanism [112, 113]. Food restriction also promotes excessive voluntary wheel running in rodents in the so-called "activitybased anorexia" model, leading to catastrophic weight loss and death, even when food access is restored [114].

Abuse of cocaine, sedatives, cannabis, heroin, and amphetamines are common in AN [115] and severity of caloric restriction is a significant predictor of psychostimulant use [116]. Around $27 \%$ of individuals with AN have a co-morbid SUD [116] with alcohol use/dependence and tobacco use the most common $[115,116]$. AN sometimes precedes a SUD, with functional use of a drug that reduces appetite (e.g. nicotine, cocaine, amphetamine) in order to enhance weight loss [117].

Psilocybin is of increasing interest in the treatment of SUDs: in a single-group proof-of-concept study alcohol-dependent patients showed decreased drinking behaviours for 8 months after one or two psilocybin sessions $[118,119]$. In another study, $80 \%$ of long-term heavy tobacco smokers demonstrated abstinence from smoking 6 months after two psilocybin doses [120]. Clinical trials are currently ongoing for treatment of cocaine use disorder (NCT02037126) and opioid use disorder (NCT04161066) in the United States.

The emerging efficacy of psilocybin in treating SUDs speaks to possible efficacy in psychiatric disorders with abnormal reward circuits, with possible lasting reductions in repetitive, compulsive, inflexible and obsessional elements present in AN. Additionally, psilocybin may directly reduce the harmful substance abuse habits that are co-morbid in many patients with the disorder.

\subsection{Autism Spectrum Disorder}

Autism spectrum disorders (ASD) are present in 23\% of AN patients and the prognosis for AN is often worse when ASD co-occurs [121]. There are many common features between AN and ASD, particularly cognitive rigidity, heightened fear and obsessive-compulsive ritualistic behaviours [122]. Psilocybin impairs recognition of fearful faces [99] and increases emotional empathy and connectedness to others, which are impaired in both ASD and AN. Although there have been no human trials, a recent preclinical study reported that psilocybin rescues sociability deficits in a mouse model of ASD [123]. Furthermore, between 1959 and 1974, 91 autistic schizophrenic children between the ages of 6 and 10 were given low to moderate doses of LSD over extended periods of time $[124,125]$. While clearly a controversial intervention, the children developed improved speech behaviour ("many seemed to comprehend speech for the first time or were able to communicate 
their needs"), increased emotional responsiveness to their peers ("They participated with increasing eagerness in motility play with adults and other children"), increased positive mood, as well as decreases in compulsive ritualistic behaviour [124]. Such reports suggest potential of classic psychedelics, including psilocybin, to ameliorate ASD symptoms in AN.

\subsection{Limitations and Significance of Outlined Studies}

Studies conducted to date with psilocybin in the areas of mental health and addiction medicine are mostly case reports, open-label feasibility and crossover trials, with very few high quality randomised double-blind controlled trials. Existing studies are prone to bias as a result of limited blinding and the frequent absence of a control group meaning that there is no objective delineation of psychedelic-induced effects. Replication of effects in larger, more rigorous, more carefully controlled studies would have significant implications for public health and clinical practice. A recent meta-analysis on classic psychedelic treatment in mood and depressive disorders concluded that despite the absence of high quality clinical trials, effects sizes remained impressive for both acute and long-term outcomes [126]. So, despite clear limitations, there is sufficient evidence to propose that psilocybin therapy might well provide an alternative treatment modality for many intractable mental health conditions that are unresponsive to conventional treatment, including AN. The large randomised controlled double-blinded trials that are ongoing for OCD (NCT03356483), cocaine use disorder (NCT02037126) and depressive disorders (NCT03866174; NCT03429075; NCT03715127; NCT03554174; NCT03380442) should help to further clarify the current picture.

\section{Psilocybin and the Neurobiology of AN}

The neural mechanisms underlying the lasting therapeutic efficacy of classic psychedelics in mental health conditions are still a matter of substantial uncertainty, although an increasing number of sophisticated brain imaging studies and other neurobiological investigations are being conducted. At the same time, the acute pharmacological actions of psychedelics on brain serotonergic systems including effects on the $5-\mathrm{HT}_{2 \mathrm{~A}}$ receptors, the key psychedelic target, are increasingly well understood. Effects of psychedelic drugs on neurotrophic growth factors and neuroplasticity are also of substantial current research interest.

\subsection{Serotonin}

Serotonin $(5-\mathrm{HT})$, an indoleamine neurotransmitter, is synthesized from the dietary amino acid tryptophan. There are more than 14 subtypes of 5-HT receptors which are regionally distributed throughout the brain and body with a wide range of functional correlates (Figure 2). The 5-HT system is implicated in appetite, mood, pain, emotion, motor function, sleep, cognition, and autonomic and neuroendocrine function [127]. 


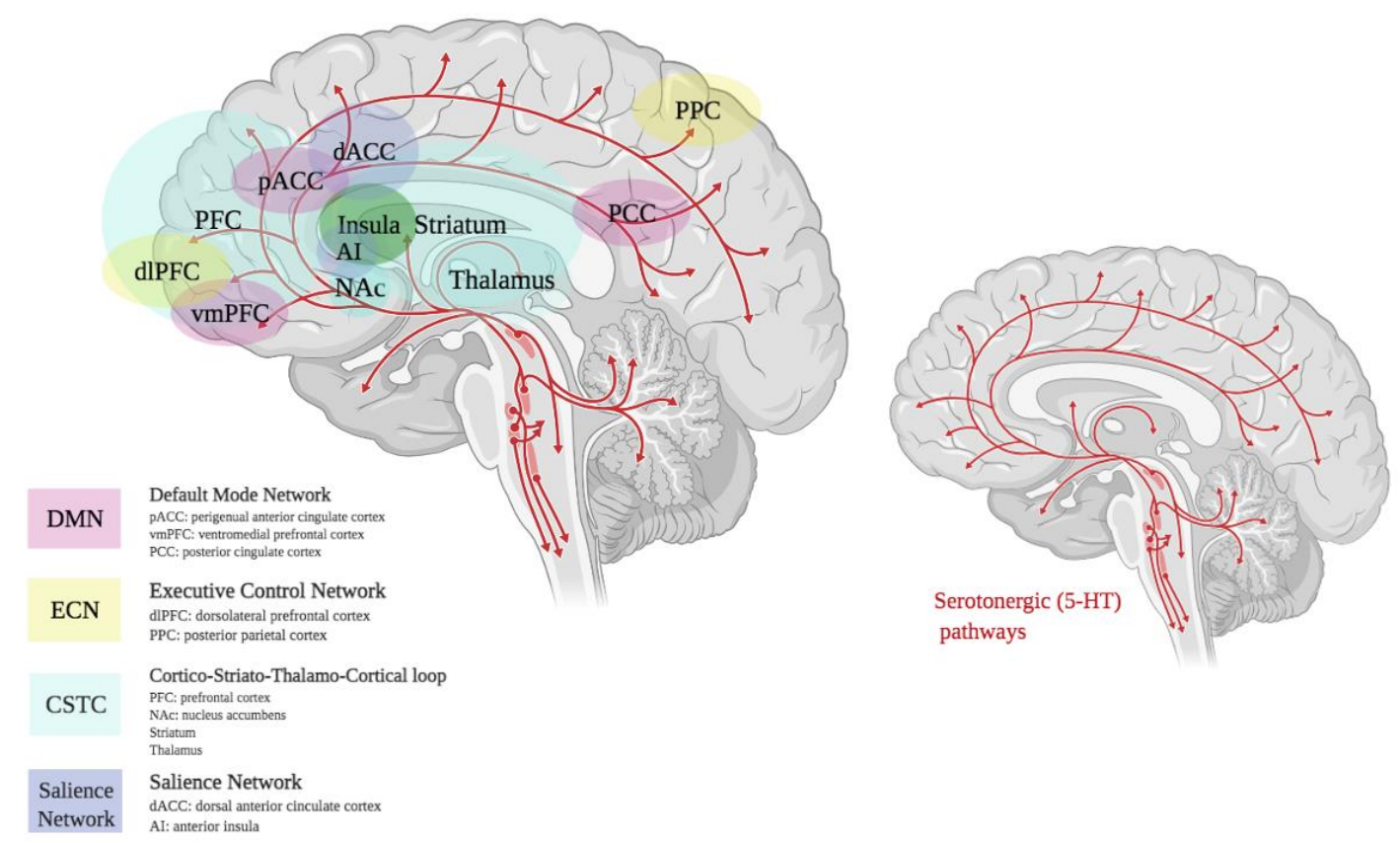

Figure 2 Psilocybin may induce pseudo-hallucinations by altering neurotransmission in corticostriato-thalamo-cortical loops. The capacity of psilocybin to modulate the default mode network (DMN) and executive control network (ECN) may underlie its lasting effects on cognitive flexibility. The DMN and ECN are major hubs that overlap with the ascending 5-HT pathways that are directly affected by classic psychedelics which target $5-\mathrm{HT}_{2 \mathrm{~A}}$ receptors richly distributed across the cortical regions where $5-\mathrm{HT}$ terminals are located.

Across many decades of preclinical and clinical research, the pharmacology of 5-HT receptors has been widely investigated in relation to obsessional behaviours, anxiety, impulse control, inhibition, attention, mood and feeding behaviour. Many prescription drugs target aspects of this complex serotonergic system including antidepressants, anxiolytics, antipsychotics, analgesics, anti-emetics, anticonvulsant, appetite suppressant and anti-migraine drugs. Serotonergic dysfunction has been reported in many disorders including depression [128], anxiety and neurosis [129], borderline personality disorder, completed suicide [129, 130] and AN [131].

Of the 14 different 5-HT receptors, it is the 5- $\mathrm{HT}_{2 \mathrm{~A}}$ receptor that is responsible for the psychedelic effects [132]. It is the primary target of all the classic psychedelic hallucinogens such as LSD, psilocybin and mescaline, as well as the synthetic $2 \mathrm{C}$ families of psychedelics [133]. Interestingly, although classic psychedelics bind with high affinity to serotonin $5-\mathrm{HT}_{2 \mathrm{~A}}$ receptors, closely related $5-\mathrm{HT}_{2 \mathrm{~A}}$ receptor agonists such as the ergot derivatives (the fungi from which LSD is derived), lisuride and ergotamine, are not necessarily hallucinogenic in humans [134]. Instead, these non-psychedelic $5-\mathrm{HT}_{2 \mathrm{~A}}$ receptor agonists have therapeutic effects in the treatment of migraines and Parkinson's disease [134]. Further, the 5-MeO-DMT derivative, 6-MeO-isoDMT, is a 5-HT2A agonist with reduced hallucinogenic effects, while maintaining the neuroplastic effects observed with 5-MeO-DMT [135].

A key location for $5-\mathrm{HT}_{2 \mathrm{~A}}$ receptors is on the apical dendrites of cortical pyramidal neurons. This location allows extensive modulation of the corticostriato-thalamo-cortical (CSTC) feedback loop by 5- $\mathrm{HT}_{2 \mathrm{~A}}$ agonists and antagonists. The CTSC loops are major networks involving the prefrontal cortex, 
striatum, nucleus accumbens and thalamus (Figure 2) $[136,137]$. The modulation of thalamocortical transmission can lead to sensory alterations known as pseudo-hallucinations [23, 138, 139]. Sensory effects include vivid internal and external imagery, illusions, visual-auditory synesthesia as well as distortions in olfactory, gustatory and tactile senses [19]. Pseudo-hallucinations are distinct from 'true' hallucinations, with the latter commonly and incorrectly used to describe the psychedelic state. A true hallucination describes an alteration in perception without a stimulus being present and a convincing reality of the experience [140]. True hallucinations are not induced by typical dosages of classic psychedelics, although are sometimes present with extremely high doses. Pseudo-hallucinations compromise vivid imagery (e.g. kaleidoscope patterns), illusions (a misinterpretation of a stimulus e.g. a crack interpreted as a snake) and visual-auditory synaesthesia (e.g. music evoking visual experiences) [138]. The extent of psilocybin-induced 5- $\mathrm{HT}_{2 \mathrm{~A}}$ receptor occupancy and plasma psilocin concentrations correlate with subjective ratings of the intensity of pseudo-hallucinations [141].

Psychiatric disorders such as OCD [142], MDD [143] and AN [144] display specific abnormalities in 5-HT signalling, and can be associated with polymorphisms of the 5-HT2A promoter (-1438G/A). Historically, depression and suicidality have also been associated with increased density of postsynaptic 5- $\mathrm{HT}_{2 \mathrm{~A}}$ receptors [145]. Some brain imaging studies have identified dysregulation 5-HT activity in frontal, cingulate, temporal, and parietal cortical regions in AN [146]. Reductions in dietary tryptophan can decrease anxiety and elevate mood in individuals with AN, suggesting serotonergic dysfunction [146]. Positron emission tomography (PET) studies have illustrated alterations in 5-HT $1 \mathrm{~A}$ and $5-\mathrm{HT}_{2 \mathrm{~A}}$ receptor and 5- $\mathrm{HT}$ transporter density in AN [147]. Some of these alterations may be a direct consequence of sustained malnutrition/starvation, reversing when weight is restored $[131,146]$. Importantly, 5-HT receptors are widely expressed in brain regions that regulate satiety, food intake and control of eating rate [148] while dysregulation of serotonin pathways in limbic structures (hippocampus, hypothalamus, amygdala, thalamus) appear to contribute to anxiety, behavioural inhibition, body image distortions, mood and impulse control in AN $[131,146]$.

It can be hypothesized then that the effects of psilocybin on $5-\mathrm{HT}_{2 \mathrm{~A}}$ (as well as $5-\mathrm{HT}_{1 \mathrm{~A}}$ and $5-\mathrm{HT}_{2 \mathrm{C}}$ ) receptors may in some way help to normalise the serotonergic system producing antidepressant and anxiolytic effects that might rescue many maladaptive mechanisms and behaviours that perpetuate illnesses such as AN [149].

\subsection{Brain Imaging Studies and Cognitive Flexibility}

The acute psychedelic state induces mystical-type experiences, emotional breakthroughs, openness, ego dissolution, feelings of unity and transcendence of time and space. fMRI studies [150, 151] have examined the neural correlates of these experiences with results painting a rather complex picture. The psychedelic states generally provide a greater repertoire of activated and connected brain states than is observed in normal waking consciousness (explained below). Increased brain connectivity, associated with increased cognitive flexibility [150], is hypothesised to 'reset' and normalise the brain, prompting significant positive changes in behaviour and long-term improvements on mental health [7, 8, 26, 37, 91, 152].

Cognitive flexibility involves the ability to adapt cognitive processing such as the capacity to rapidly switch thinking between multiple concepts [153]. It is an executive function that allows 
adaptation to and learning from a change in environmental contingencies and to overcome habitual and repetitive rigidified thoughts. Cognitive inflexibility is a key phenotype in AN and contributes to severe anxiety, obsessiveness, impulsive and compulsive behaviours to control weight and food consumption [154-156]. Such behaviours include fixations on calorie-counting, focus on intense exercises as well as restraint in emotional expression, severe anxiety, social introversion, body image disturbances, and obsessions related to perfectionism, symmetry, exactness, and order [122, $146,156]$. These habits often persist after recovery $[146,155,156]$ and cognitive inflexibility has been demonstrated in healthy sisters of AN patients [157] implying further etiological relevance. Cognitive rigidity in AN decreases engagement to treatment that aims to dismantle rigidified beliefs that perpetuate the illness [54, 122, 156, 158].

The insula, a brain region that plays a critical role in switching between the salience network, executive control network (ECN) and default mode network (DMN) (Figure 2), known as the 'connector hubs' [159]. The ECN is important for the integration of sensory and memory information, regulation of cognition and behaviour as well as cognitive flexibility [153]. The DMN is characterised by self-referential activity, and is particularly active at resting state [160] whereas the salience network is believed to be important for self-awareness, higher cognition and ego-vitality [161].

$\mathrm{fMRI}$ studies show that psilocybin decreases brain activity in the salience network, ECN and DMN $[150,151,162,163]$. By 'switching off' these connector hubs, connectivity is thought to increase between them allowing for increasingly fluid modes of cognition throughout the brain $[38,150,151$, $163,164]$. This wider repertoire of connectivity may allow individuals an opportunity to make changes in their personal life and outlook that were previously not possible [34, 104, 105]. An increase in cognitive flexibility constitutes a major psychological mechanism causing psilocybin's therapeutic effects $[28,34,35,37,38,104-106,151,165]$. This increased connectivity across brain networks, which is maintained at 1-week and 1-month post-psilocybin, is consistent with the positive psychological effects, indicating enhanced brain plasticity [166].

Increased cognitive flexibility may well be central to psilocybin's anti-depressant and anxiolytic effects [167], and have potential to reduce suicidality, treatment-resistance and relapse in AN [168]. This therapeutic window induced by psilocybin may help individuals with AN to address and dismantle severely rigidified thought patterns that drive the illness, reducing maladaptive eatingrelated and co-morbid behaviours.

\subsection{Brain Plasticity and Neurotrophic Factors}

Change in cognitive flexibility is one example of the broader concept of neuroplasticity, referring to the fundamental ability of the brain to reorganise its structure and connections in response to environmental stimuli and internal neurodevelopmental sequences. This property underpins learning and memory, brain development, homeostasis and recovery from brain damage. Neuroplastic changes include the formation of new neurons (neurogenesis), the formation of new neuronal connections during development, and cortical reorganisation.

Central to neuroplasticity are growth factors including brain derived neurotrophic factor (BDNF) and glial cell line-derived neurotrophic factor (GDNF). These are important for survival and function of neurons and to brain plasticity, and are widely implicated in reward processing and learning and 
memory [169]. BDNF also regulates energy homeostasis, food intake, satiety, weight maintenance [170-172] and exhibits antidepressant effects [173].

There is evidence that neuroplasticity is impaired in AN and this may correlate with cognitive inflexibility. Reductions in grey and white matter volumes have been identified AN [146, 174-176]. BDNF gene polymorphisms are associated with AN patients $[177,178]$ as well as low levels of BDNF itself $[175,179,180]$. Reduced levels of both GDNF and BDNF are also found in patients with anxiety disorders [181], mood disorders [182, 183] and in SUD [169, 184].

In vitro and in vivo evidence suggests that classic psychedelics are capable of increasing concentrations of neurotrophic factors such as BDNF and GDNF [185-187] and that this may correlate with changes in brain plasticity and the long-term antidepressant, anxiolytic and antiaddiction effects reported with psilocybin. The remarkable ability of psilocybin to promote lasting changes in mood and cognition, long after the drug has been eliminated from the body, is consistent with long-term changes in brain plasticity [166].

\section{Safety of Psilocybin}

Access to psilocybin is highly restricted in most countries. It is typically illegal to produce, own or supply psilocybin and the drug is often classified in a way that implies it has no medical value and a high risk of abuse. This contrasts with the majority of scientific and clinical evidence suggesting that psilocybin is in generally safe and actually has a very low risk of abuse $[111,188,189]$. No overdoserelated deaths have been reported from classic psychedelics and psilocybin has a very high safety and low risk profile in a clinical settings, with reasonable safety even in unsupervised naturalistic settings [190]. An analysis of harms conducted by Nutt et al. (2010) ranked psilocybin one of the least harmful recreational and prescription drugs both in terms of harm to self and harm to others [10].

There is no evidence of physical dependence on psilocybin (as shown by withdrawal symptoms) and the drug is typically not rewarding in animal models of addiction [189]. Tolerance to psilocybin builds up rapidly thus further reducing the potential to be used regularly and abused [188]. The metabolites of psilocybin/psilocin exhibit low toxicity and do not accumulate in the body [20, 24]. Psilocin is largely excreted after 3 hours, completely eliminated after 24 hours with a half-life of 2.53 hours [22, 24].

Psilocybin and other classic psychedelics have sometimes been thought to provide a model of psychosis. Even when individuals are having an overall positive drug experience with psychedelics, they can show increased delusional thinking, cognitive disorganisation and paranoia, all of which are hallmarks of a psychotic state. However, actual psychosis usually involves a lack of insight into the condition and this is not represented in the psychedelic state $[5,140]$. Further, there is no wellestablished link between psilocybin use and the lasting induction of psychosis, and there is no link with induction of depression, anxiety disorders or suicidal ideation [11,111, 191]. Such hazards are further prevented in clinical trials by the strict exclusion of individuals with current schizophrenia spectrum or bipolar disorders as well as their first- and second-degree relations.

Physiological changes including transient increases in heart rate and blood pressure are common with psychedelics, although such changes do not occur at hazardous levels in clinical trials [188]. To ensure patient safety, blood pressure and heart rate are continuously measured during a psilocybin 
dosing session and individuals who are not medically stable, especially those with compromised cardiovascular function, are strictly excluded from trials [188].

Common psychological adverse effects noted in clinical trials include transient anxiety, fear, nausea, paranoia and post-treatment headaches. Griffiths et al. (2011) conducted a study with varying ascending and descending dose of psilocybin. One particular patient experienced sustained anxiety at $30 \mathrm{mg} / 70 \mathrm{~kg}$ and described it as one of the worst experiences of her life. This patient, however, continued with the study and eventually fulfilled criteria for a complete mystical experience. One month post-dosing she retrospectively rated the experience as the single most personally meaningful and spiritual of her life [26]. During this study, multiple patients reported high levels of fear, anxiety and paranoia. However, no volunteers rated the experience as having decreased their sense of well-being or life-satisfaction [26], with 83\% rating it the most, or amongst the top five, spiritually significant experiences of their lifetime. Interestingly this increased to $94 \%$ at 14-month follow up. Most volunteers reported the challenging experiences as in fact being incredibly effective and having long term benefits [26]. A patient with an eating disorder reported following an ayahuasca session "I had a really, really tough experience but I'm so grateful because I feel 10 times lighter. And that doesn't have to do with just my body image, it's emotionally, it's like that stuff that I couldn't get to, that I can't touch with other methods" [76].

Similarly, as noted above, a recent survey $(\mathrm{N}=1993)$ uncovered many users who experienced psychological difficulties or challenging experiences following the ingestion of psilocybin mushrooms. While a substantial percentage encountered lasting difficulties, at least $84 \%$ stated that they actually benefitted from the challenging experience [41].

Given that risks of adverse events heighten as dosage increases, there is increasing interest in the idea of microdosing (the use of ultra-low doses of psychedelics). Recent studies suggest increasing creativity, optimism, cognitive functioning, emotional balance, physical stamina as well as decreasing social anxiety and depressive symptoms with such low doses [192, 193]. A key question is whether a fully-fledged psychedelic experience is required for the effective treatment of refractory psychiatric conditions. Hutten et al. (2019) suggest that lower doses have less efficacy in treating mental health problems such as anxiety and depression relative to regular larger psychedelic doses. Griffiths et al. (2016) reported that higher doses had increased efficacy for reduction of depressive and anxiety symptoms compared to low doses. At 5 weeks post psilocybin exposure, $92 \%$ compared to $35 \%$ had clinically significant improvements in depression scores while $76 \%$ compared to $24 \%$ had improved anxiety scores.

Ultimately, preparation, support and integration (PSI) (before, during and post psychedelic session), appropriate supervision (psychiatrist/ psychologist/ trained therapist, physician) and 'set and setting' should be always adhered to in a clinical setting that ensure the safety of patients during and after a psychedelic therapy session.

\section{Conclusions and Future Research}

The current review argues that psilocybin is a safe intervention when administered in a carefully controlled clinical setting and has notable therapeutic potential in a range of severe refractory psychiatric illnesses. The unique rapidity and long-term durability of psilocybin's effects in studies to date indicates much-needed novel, rapid-acting and potentially cost-effective enhancement to current approaches. The use of psilocybin as an adjunct to current psychotherapy treatment 
modalities in AN is a particularly attractive proposition. The neurobiological and behavioural phenotype of AN, specifically with respect to co-occurring diagnoses, serotonergic dysfunction, and deficits in cognitive flexibility and neuroplasticity, provides strong impetus to the application of psilocybin treatment to this intractable condition.

Accordingly, Imperial College (London), John Hopkins University (Baltimore) and the University of California (San Diego) have recently approved phase 1 clinical trials to examine safety and efficacy of psilocybin in AN. They are small, uncontrolled, non-blinded open-label trials with adjunctive use of psilocybin alongside short-term standard psychotherapies. Clearly, despite the inherent difficulty involving in designing proper placebo-controlled double-blind clinical trials with a psychedelic substance, such trials are necessary to strengthen our knowledge and to support future evidencebased clinical practice. Future studies will be required to answer key questions as follows:

Can psilocybin, when used as an adjunct to psychological interventions, increase treatment acceptance, improve post-treatment remission rates and decrease dropout and relapse rates in treatment-refractory AN?

Can psilocybin, when used as an adjunct to psychological interventions, reduce AN psychopathology and symptoms of co-morbid conditions?

Can psilocybin, when used as an adjunct to psychological interventions, promote weight gain and recovery?

Although this paper has predominantly focused on psilocybin and AN, classic psychedelics including LSD, DMT, 5-MeO-DMT and mescaline warrant further exploration for therapeutic use in AN. The therapeutic efficacy of psychedelics in other related eating-disorders including atypical-AN, bulimia nervosa and binge eating disorder is also worthy of future investigation.

\section{Methodology}

Literature searches for this paper included using search terms relevant to classic psychedelics and eating disorders, such as "psilocybin" AND (depression* OR anxiety* OR substance abuse disorders* OR PTSD* OR autism spectrum disorder* OR neuroplasticity* OR safety* OR eating disorders*), "anorexia nervosa" AND (psychotherapy* OR pharmacological treatments* OR cognitive flexibility* OR serotonin* OR co-morbidities* OR treatment-resistant*). Peer-reviewed papers of original research, reviews, case-reports and studies on animal models were all included. The literature included in this review was received through searches of databases such as PubMed, ScienceDirect, SpringerLink and Elsevier.

\section{Acknowledgments}

The authors acknowledge BioRender.com for resources used in the making of the figures.

\section{Author Contributions}

SR conducted the review and prepared the first draft of the manuscript and reviewed data relating to the research priorities. PA, ISM, and SM contributed extensively to the direction and editing of the first draft and provided guidance and supervision throughout the process.

\section{Competing Interests}


The authors have declared that no competing interests exist.

\section{References}

1. Samorini G. The oldest archeological data evidencing the relationship of Homo sapiens with psychoactive plants: A worldwide overview. J Psychedelic Stud. 2019; 3: 63-80.

2. Guerra-Doce E. Psychoactive substances in prehistoric times: Examining the archaeological evidence. Time Mind. 2015; 8: 91-112.

3. Guzmán G. Hallucinogenic mushrooms in Mexico: An overview. Econ Bot. 2008; 62: 404-412.

4. McKenna D, Riba J. New world tryptamine hallucinogens and the neuroscience of ayahuasca. Behav Neurobiol Psychedelic Drugs. 2016; 36: 283-311.

5. Sessa B. The history of psychedelics in medicine. In: Handbuch Psychoaktive Substanzen. Berlin: Springer; 2016. p.1-26.

6. Moreno FA. Hallucinogen-induced relief of obsessions and compulsions. Am J Psychiatry. 1997; 154: 1037-1038.

7. Griffiths RR, Richards WA, Johnson MW, McCann UD, Jesse R. Mystical-type experiences occasioned by psilocybin mediate the attribution of personal meaning and spiritual significance 14 months later. J Psychopharmacol. 2008; 22: 621-632.

8. Griffiths RR, Richards WA, McCann U, Jesse R. Psilocybin can occasion mystical-type experiences having substantial and sustained personal meaning and spiritual significance. Psychopharmacology. 2006; 187: 268-283.

9. Schmid $Y$, Gasser P, Oehen P, Liechti ME. Acute subjective effects in LSD-and MDMA-assisted psychotherapy. J Psychopharmacol. 2021: 35: 362-374.

10. Nutt DJ, King LA, Phillips LD. Drug harms in the UK: A multicriteria decision analysis. Lancet. 2010; 376: 1558-1565.

11. Johansen $P \varnothing$, Krebs TS. Psychedelics not linked to mental health problems or suicidal behavior: A population study. J Psychopharmacol. 2015; 29: 270-279.

12. Krebs TS, Johansen $P \varnothing$. Lysergic acid diethylamide (LSD) for alcoholism: Meta-analysis of randomized controlled trials. J Psychopharmacol. 2012; 26: 994-1002.

13. Fuentes JJ, Fonseca F, Elices M, Farré M, Torrens M. Therapeutic use of LSD in psychiatry: A systematic review of randomized-controlled clinical trials. Front Psychiatry. 2020; 10: 943.

14. Davis AK, Averill LA, Sepeda ND, Barsuglia JP, Amoroso T. Psychedelic treatment for traumarelated psychological and cognitive impairment among US Special Operations Forces Veterans. Chronic Stress. 2020; 4: 2470547020939564.

15. Davis AK, Barsuglia JP, Lancelotta R, Grant RM, Renn E. The epidemiology of 5-methoxy-N, Ndimethyltryptamine (5-MeO-DMT) use: Benefits, consequences, patterns of use, subjective effects, and reasons for consumption. J Psychopharmacol. 2018; 32: 779-792.

16. Davis AK, So S, Lancelotta R, Barsuglia JP, Griffiths RR. 5-methoxy-N, N-dimethyltryptamine (5MeO-DMT) used in a naturalistic group setting is associated with unintended improvements in depression and anxiety. Am J Drug Alcohol Abuse. 2019; 45: 161-169.

17. Giovannetti C, Garcia Arce S, Rush B, Mendive F. Pilot evaluation of a residential drug addiction treatment combining traditional amazonian medicine, ayahuasca and psychotherapy on depression and anxiety. J Psychoact Drugs. 2020; 52: 472-481. 
18. Geiger HA, Wurst MG, Daniels RN. DARK classics in chemical neuroscience: Psilocybin. ACS Chem Neurosci. 2018; 9: 2438-2447.

19. Nichols DE. Psychedelics. Pharmacol Rev. 2016; 68: 264-355.

20. Passie T, Seifert J, Schneider U, Emrich HM. The pharmacology of psilocybin. Addict Biol. 2002; 7: 357-364.

21. Halberstadt AL. Recent advances in the neuropsychopharmacology of serotonergic hallucinogens. Behav Brain Res. 2015; 277: 99-120.

22. Tylš $F$, Páleníček $T$, Horáček J. Psilocybin-summary of knowledge and new perspectives. Eur Neuropsychopharmacol. 2014; 24: 342-356.

23. Studerus E, Kometer M, Hasler F, Vollenweider FX. Acute, subacute and long-term subjective effects of psilocybin in healthy humans: A pooled analysis of experimental studies. J Psychopharmacol. 2011; 25: 1434-1452.

24. Brown RT, Nicholas CR, Cozzi NV, Gassman MC, Cooper KM, Muller D, et al. Pharmacokinetics of escalating doses of oral psilocybin in healthy adults. Clin Pharmacokinet. 2017; 56: 15431554.

25. Nicholas CR, Henriquez KM, Gassman MC, Cooper KM, Muller D, Hetzel S, et al. High dose psilocybin is associated with positive subjective effects in healthy volunteers. J Psychopharmacol. 2018; 32: 770-778.

26. Griffiths RR, Johnson MW, Richards WA, Richards BD, McCann U, Jesse R. Psilocybin occasioned mystical-type experiences: Immediate and persisting dose-related effects. Psychopharmacology. 2011; 218: 649-665.

27. MacLean KA, Johnson MW, Griffiths RR. Mystical experiences occasioned by the hallucinogen psilocybin lead to increases in the personality domain of openness. J Psychopharmacol. 2011; 25: 1453-1461.

28. Agin-Liebes GI, Malone T, Yalch MM, Mennenga SE, Ponté KL, Guss J, et al. Long-term followup of psilocybin-assisted psychotherapy for psychiatric and existential distress in patients with life-threatening cancer. J Psychopharmacol. 2020; 34: 155-166.

29. Pokorny T, Preller KH, Kometer M, Dziobek I, Vollenweider FX. Effect of psilocybin on empathy and moral decision-making. Int J Neuropsychopharmacol. 2017; 20: 747-757.

30. Mason NL, Mischler E, Uthaug MV, Kuypers KP. Sub-acute effects of psilocybin on empathy, creative thinking, and subjective well-being. J Psychoact Drugs. 2019; 51: 123-134.

31. Kuypers KPC. Out of the box: A psychedelic model to study the creative mind. Med Hypotheses. 2018; 115: 13-16.

32. Smigielski L, Kometer $M$, Scheidegger $M$, Krähenmann $R$, Huber $T$, Vollenweider $F X$. Characterization and prediction of acute and sustained response to psychedelic psilocybin in a mindfulness group retreat. Sci Rep. 2019; 9: 1-13.

33. Kometer M, Pokorny T, Seifritz E, Volleinweider FX. Psilocybin-induced spiritual experiences and insightfulness are associated with synchronization of neuronal oscillations. Psychopharmacology. 2015; 232: 3663-3676.

34. Carhart-Harris RL, Roseman L, Bolstridge M, Demetriou L, Pannekoek JN, Wall MB, et al. Psilocybin for treatment-resistant depression: fMRI-measured brain mechanisms. Sci Rep. 2017; 7: 1-11. 
35. Watts R, Day C, Krzanowski J, Nutt D, Carhart-Harris R. Patients' accounts of increased "connectedness" and "acceptance" after psilocybin for treatment-resistant depression. J Humanist Psychol. 2017; 57: 520-564.

36. Zeifman RJ, Wagner AC, Watts R, Kettner H, Mertens LJ, Carhart-Harris RL. Post-psychedelic reductions in experiential avoidance are associated with decreases in depression severity and suicidal ideation. Front Psychiatry. 2020; 11: 782.

37. Erritzoe D, Roseman L, Nour MM, MacLean K, Kaelen M, Nutt DJ, et al. Effects of psilocybin therapy on personality structure. Acta Psychiatr Scand. 2018; 138: 368-378.

38. Roseman L, Haijen E, Idialu-Ikato K, Kaelen M, Watts R, Carhart-Harris R. Emotional breakthrough and psychedelics: Validation of the Emotional Breakthrough Inventory. J Psychopharmacol. 2019; 33: 1076-1087.

39. De Gregorio D, Comai S, Posa L, Gobbi G. d-Lysergic acid diethylamide (LSD) as a model of psychosis: Mechanism of action and pharmacology. Int J Mol Sci. 2016; 17: 1953.

40. Ungerleider JT, Fisher DD, Fuller M, Caldwell A. The "bad trip" -- the etiology of the adverse LSD reaction. Am J Psychiatry. 1968; 124: 1483-1490.

41. Carbonaro TM, Bradstreet MP, Barrett FS, MacLean KA, Jesse R, Johnson MW, et al. Survey study of challenging experiences after ingesting psilocybin mushrooms: Acute and enduring positive and negative consequences. J Psychopharmacol. 2016; 30: 1268-1278.

42. Galmiche M, Déchelotte $P$, Lambert G, Tavolacci MP. Prevalence of eating disorders over the 2000-2018 period: A systematic literature review. Am J Clin Nutri. 2019; 109: 1402-1413.

43. American Psychiatric Association A, American Psychiatric Association. Diagnostic and statistical manual of mental disorders: DSM-5. Arlington: American Psychiatric Association; 2013.

44. Keating C, Tilbrook AJ, Rossell SL, Enticott PG, Fitzgerald PB. Reward processing in anorexia nervosa. Neuropsychologia. 2012; 50: 567-575.

45. Keshaviah A, Edkins K, Hastings ER, Krishna M, Franko DL, Herzog DB, et al. Re-examining premature mortality in anorexia nervosa: A meta-analysis redux. Compr Psychiatry. 2014; 55: 1773-1784.

46. Arcelus J, Mitchell AJ, Wales J, Nielsen S. Mortality rates in patients with anorexia nervosa and other eating disorders: A meta-analysis of 36 studies. Arch Gen Psychiatry. 2011; 68: 724-731.

47. Touyz S, Le Grange D, Lacey $H$, Hay P, Smith R, Maguire $S$, et al. Treating severe and enduring anorexia nervosa: A randomized controlled trial. Psychol Med. 2013; 43: 2501.

48. Eddy KT, Tabri N, Thomas JJ, Murray HB, Keshaviah A, Hastings E, et al. Recovery from anorexia nervosa and bulimia nervosa at 22-year follow-up. J Clin Psychiatry. 2017; 78: 184-189.

49. Halmi KA, Agras WS, Crow S, Mitchell J, Wilson GT, Bryson SW, et al. Predictors of treatment acceptance and completion in anorexia nervosa: Implications for future study designs. Arch Gen Psychiatry. 2005; 62: 776-781.

50. Bamford BH, Mountford VA. Cognitive behavioural therapy for individuals with longstanding anorexia nervosa: Adaptations, clinician survival and system issues. Eur Eat Disord Rev. 2012; 20: 49-59.

51. Fairburn CG, Cooper Z, Doll HA, O'Connor ME, Palmer RL, Dalle Grave R. Enhanced cognitive behaviour therapy for adults with anorexia nervosa: A UK-Italy study. Behav Res Ther. 2013; 51: R2-R8.

52. Karlsson GP, Clinton D, Nevonen L. Prediction of weight increase in anorexia nervosa. Nord J Psychiatry. 2013; 67: 424-432. 
53. Carter JC, Mercer-Lynn KB, Norwood SJ, Bewell-Weiss CV, Crosby RD, Woodside DB, et al. A prospective study of predictors of relapse in anorexia nervosa: Implications for relapse prevention. Psychiatry Res. 2012; 200: 518-523.

54. Abbate-Daga G, Amianto F, Delsedime N, De-Bacco C, Fassino S. Resistance to treatment and change in anorexia nervosa: A clinical overview. BMC Psychiatry. 2013; 13: 1-18.

55. Pike KM, Walsh BT, Vitousek K, Wilson GT, Bauer J. Cognitive behavior therapy in the posthospitalization treatment of anorexia nervosa. Am J Psychiatry. 2003; 160: 2046-2049.

56. Fairburn CG. Cognitive behavior therapy and eating disorders. London: Guilford Press; 2008. p.324.

57. Schmidt U, Wade TD, Treasure J. The Maudsley Model of Anorexia Nervosa Treatment for Adults (MANTRA): Development, key features, and preliminary evidence. J Cogn Psychother. 2014; 28: 48-71.

58. Byrne S, Wade T, Hay P, Touyz S, Fairburn CG, Treasure J, et al. A randomised controlled trial of three psychological treatments for anorexia nervosa. Psychol Med. 2017; 47: 2823-2833.

59. Byrne SM, Fursland A, Allen KL, Watson $H$. The effectiveness of enhanced cognitive behavioural therapy for eating disorders: An open trial. Behav Res Ther. 2011; 49: 219-226.

60. Calugi S, Dalle Grave R, Sartirana M, Fairburn CG. Time to restore body weight in adults and adolescents receiving cognitive behaviour therapy for anorexia nervosa. J Eat Disord. 2015; 3: 1-6.

61. Himmerich H, Kan C, Au K, Treasure J. Pharmacological treatment of eating disorders, comorbid mental health problems, malnutrition and physical health consequences. Pharmacol Ther. 2021; 217: 107667.

62. Trunko ME, Schwartz TA, Duvvuri V, Kaye WH. Aripiprazole in anorexia nervosa and low-weight bulimia nervosa. Int J Eat Disord. 2011; 44: 269-275.

63. Frank GK, Shott ME, Hagman JO, Schiel MA, DeGuzman MC, Rossi B. The partial dopamine D2 receptor agonist aripiprazole is associated with weight gain in adolescent anorexia nervosa. Int J Eat Disord. 2017; 50: 447-450.

64. Attia E, Steinglass JE, Walsh BT, Wang Y, Wu P, Schreyer C, et al. Olanzapine versus placebo in adult outpatients with anorexia nervosa: A randomized clinical trial. Am J Psychiatry. 2019; 176: 449-456.

65. Çöpür S, Çöpür M. Olanzapine in the treatment of anorexia nervosa: A systematic review. Egypt J Neurol Psychiatr Neurosurg. 2020; 56: 1-7.

66. Marvanova M, Gramith K. Role of antidepressants in the treatment of adults with anorexia nervosa. Ment Health Clin. 2018; 8: 127-137.

67. Frank GK, Shott ME. The role of psychotropic medications in the management of anorexia nervosa: Rationale, evidence and future prospects. CNS Drugs. 2016; 30: 419-442.

68. Kaye WH, Nagata T, Weltzin TE, Hsu LG, Sokol MS, McConaha C, et al. Double-blind placebocontrolled administration of fluoxetine in restricting-and restricting-purging-type anorexia nervosa. Biol Psychiatry. 2001; 49: 644-652.

69. Walsh BT, Kaplan AS, Attia E, Olmsted M, Parides M, Carter JC, et al. Fluoxetine after weight restoration in anorexia nervosa: A randomized controlled trial. JAMA. 2006; 295: 2605-2612.

70. Marzola E, Desedime N, Giovannone C, Amianto F, Fassino S, Abbate-Daga G. Atypical antipsychotics as augmentation therapy in anorexia nervosa. PLoS One. 2015; 10: e0125569. 
71. Cassioli E, Sensi C, Mannucci E, Ricca V, Rotella F. Pharmacological treatment of acute-phase anorexia nervosa: Evidence from randomized controlled trials. J Psychopharmacol. 2020; 34: 864-873.

72. Kim YR, Kim CH, Cardi V, Eom JS, Seong Y, Treasure J. Intranasal oxytocin attenuates attentional bias for eating and fat shape stimuli in patients with anorexia nervosa. Psychoneuroendocrinology. 2014; 44: 133-142.

73. Russell J, Maguire S, Hunt GE, Kesby A, Suraev A, Stuart J, et al. Intranasal oxytocin in the treatment of anorexia nervosa: Randomized controlled trial during re-feeding. Psychoneuroendocrinology. 2018; 87: 83-92.

74. Banister SD, Arnold JC, Connor M, Glass M, McGregor IS. Dark classics in chemical neuroscience: $\triangle 9$-tetrahydrocannabinol. ACS Chem Neurosci. 2019; 10: 2160-2175.

75. Andries A, Frystyk J, Flyvbjerg A, St øving RK. Dronabinol in severe, enduring anorexia nervosa: A randomized controlled trial. Int J Eat Disord. 2014; 47: 18-23.

76. Renelli M, Fletcher J, Tupper KW, Files N, Loizaga-Velder A, Lafrance A. An exploratory study of experiences with conventional eating disorder treatment and ceremonial ayahuasca for the healing of eating disorders. Eat Weight Disord. 2020; 25: 437-444.

77. Steiger $\mathrm{H}$. Eating disorders and the serotonin connection: State, trait and developmental effects. J Psychiatry Neurosci. 2004; 29: 20-29.

78. Halmi KA. Perplexities of treatment resistence in eating disorders. BMC psychiatry. 2013; 13: 16.

79. Godart NT, Flament MF, Perdereau F, Jeammet P. Comorbidity between eating disorders and anxiety disorders: A review. Int J Eat Disord. 2002; 32: 253-270.

80. Kaye WH, Bulik CM, Thornton L, Barbarich N, Masters K, Price Foundation Collaborative Group. Comorbidity of anxiety disorders with anorexia and bulimia nervosa. Am J Psychiatry. 2004; 161: 2215-2221.

81. Swinbourne J, Hunt C, Abbott M, Russell J, St Clare T, Touyz S. The comorbidity between eating disorders and anxiety disorders: Prevalence in an eating disorder sample and anxiety disorder sample. Aust N Z J Psychiatry. 2012; 46: 118-131.

82. Swinbourne JM, Touyz SW. The co-morbidity of eating disorders and anxiety disorders: A review. Eur Eat Disord Rev. 2007; 15: 253-274.

83. Yilmaz Z, Halvorsen M, Bryois J, Yu D, Thornton LM, Zerwas S, et al. Examination of the shared genetic basis of anorexia nervosa and obsessive-compulsive disorder. Mol Psychiatry. 2020; 25: 2036-2046.

84. Watson HJ, Yilmaz Z, Thornton LM, Hübel C, Coleman JR, Gaspar HA, et al. Genome-wide association study identifies eight risk loci and implicates metabo-psychiatric origins for anorexia nervosa. Nat Genet. 2019; 51: 1207-1214.

85. Yackobovitch-Gavan M, Golan M, Valevski A, Kreitler S, Bachar E, Lieblich A, et al. An integrative quantitative model of factors influencing the course of anorexia nervosa over time. Int $J$ Eat Disord. 2009; 42: 306-317.

86. Dellava JE, Kendler KS, Neale MC. Generalized anxiety disorder and anorexia nervosa: Evidence of shared genetic variation. Depress Anxiety. 2011; 28: 728-733.

87. Dellava JE, Thornton LM, Hamer RM, Strober M, Plotnicov K, Klump KL, et al. Childhood anxiety associated with low BMI in women with anorexia nervosa. Behav Res Ther. 2010; 48: 60-67. 
88. Raney TJ, Thornton LM, Berrettini W, Brandt H, Crawford S, Fichter MM, et al. Influence of overanxious disorder of childhood on the expression of anorexia nervosa. Int J Eat Disord. 2008; 41: 326-332.

89. Moreno FA, Wiegand CB, Taitano EK, Delgado PL. Safety, tolerability, and efficacy of psilocybin in 9 patients with obsessive-compulsive disorder. J Clin Psychiatry. 2006; 67: 1735-1740.

90. Grob CS, Danforth AL, Chopra GS, Hagerty M, McKay CR, Halberstadt AL, et al. Pilot study of psilocybin treatment for anxiety in patients with advanced-stage cancer. Arch Gen Psychiatry. 2011; 68: 71-78.

91. Griffiths RR, Johnson MW, Carducci MA, Umbricht A, Richards WA, Richards BD, et al. Psilocybin produces substantial and sustained decreases in depression and anxiety in patients with lifethreatening cancer: A randomized double-blind trial. J Psychopharmacol. 2016; 30: 1181-1197.

92. Fuglset TS, Landr $\varnothing \mathrm{NI}$, Reas DL, Rø $\varnothing$. Functional brain alterations in anorexia nervosa: A scoping review. J Eat Disord. 2016; 4: 1-13.

93. Tagay S, Schlegl S, Senf W. Traumatic events, posttraumatic stress symptomatology and somatoform symptoms in eating disorder patients. Eur Eat Disord Rev. 2010; 18: 124-132.

94. Reyes-Rodríguez ML, Ann Von Holle T, Thornton LM, Klump KL, Brandt H, Crawford S, et al. Posttraumatic stress disorder in anorexia nervosa. Psychosom Med. 2011; 73: 491-497.

95. Tagay S, Schlottbohm E, Reyes-Rodriguez ML, Repic N, Senf W. Eating disorders, trauma, PTSD, and psychosocial resources. Eat Disord. 2014; 22: 33-49.

96. Kraehenmann R, Preller KH, Scheidegger M, Pokorny T, Bosch OG, Seifritz E, et al. Psilocybininduced decrease in amygdala reactivity correlates with enhanced positive mood in healthy volunteers. Biol Psychiatry. 2015; 78: 572-581.

97. Kraehenmann R, Schmidt A, Friston K, Preller KH, Seifritz E, Vollenweider FX. The mixed serotonin receptor agonist psilocybin reduces threat-induced modulation of amygdala connectivity. Neurolmage Clin. 2016; 11: 53-60.

98. Krediet E, Bostoen T, Breeksema J, van Schagen A, Passie T, Vermetten E. Reviewing the potential of psychedelics for the treatment of PTSD. Int J Neuropsychopharmacol. 2020; 23: 385-400.

99. Schmidt A, Kometer M, Bachmann R, Seifritz E, Vollenweider F. The NMDA antagonist ketamine and the $5-\mathrm{HT}$ agonist psilocybin produce dissociable effects on structural encoding of emotional face expressions. Psychopharmacology. 2013; 225: 227-239.

100.Kometer M, Schmidt A, Bachmann R, Studerus E, Seifritz E, Vollenweider FX. Psilocybin biases facial recognition, goal-directed behavior, and mood state toward positive relative to negative emotions through different serotonergic subreceptors. Biol Psychiatry. 2012; 72: 898-906.

101.Catlow BJ, Song S, Paredes DA, Kirstein CL, Sanchez-Ramos J. Effects of psilocybin on hippocampal neurogenesis and extinction of trace fear conditioning. Exp Brain Res. 2013; 228: 481-491.

102. Thornton LM, Welch E, Munn-Chernoff MA, Lichtenstein P, Bulik CM. Anorexia nervosa, major depression, and suicide attempts: Shared genetic factors. Suicide Life-Threat Behav. 2016; 46: 525-534.

103.Bulik CM, Thornton L, Pinheiro AP, Plotnicov K, Klump KL, Brandt $H$, et al. Suicide attempts in anorexia nervosa. Psychosom Med. 2008; 70: 378-383. 
104.Carhart-Harris RL, Bolstridge M, Rucker J, Day CM, Erritzoe D, Kaelen M, et al. Psilocybin with psychological support for treatment-resistant depression: An open-label feasibility study. Lancet Psychiatry. 2016; 3: 619-627.

105.Carhart-Harris RL, Bolstridge M, Day CM, Rucker J, Watts R, Erritzoe DE, et al. Psilocybin with psychological support for treatment-resistant depression: Six-month follow-up. Psychopharmacology. 2018; 235: 399-408.

106.Roseman L, Nutt DJ, Carhart-Harris RL. Quality of acute psychedelic experience predicts therapeutic efficacy of psilocybin for treatment-resistant depression. Front Parmacol. 2018; 8: 974.

107.Carhart-Harris R, Giribaldi B, Watts R, Baker-Jones M, Murphy-Beiner A, Murphy R, et al. Trial of psilocybin versus escitalopram for depression. N Engl J Med. 2021; 384: 1402-1411.

108. Ross S, Bossis A, Guss J, Agin-Liebes G, Malone T, Cohen B, et al. Rapid and sustained symptom reduction following psilocybin treatment for anxiety and depression in patients with lifethreatening cancer: A randomized controlled trial. J Psychopharmacol. 2016; 30: 1165-1180.

109. Rasic DT, Belik SL, Elias B, Katz LY, Enns M, Sareen J, et al. Spirituality, religion and suicidal behavior in a nationally representative sample. J Affect Disord. 2009; 114: 32-40.

110.Weber SR, Pargament KI. The role of religion and spirituality in mental health. Curr Opin Psychiatry. 2014; 27: 358-363.

111. Hendricks PS, Thorne CB, Clark CB, Coombs DW, Johnson MW. Classic psychedelic use is associated with reduced psychological distress and suicidality in the United States adult population. J Psychopharmacol. 2015; 29: 280-288.

112.Carr KD. Augmentation of drug reward by chronic food restriction: Behavioral evidence and underlying mechanisms. Physiol Behav. 2002; 76: 353-364.

113.Carr KD, Kim GY, de Vaca SC. Chronic food restriction in rats augments the central rewarding effect of cocaine and the $\delta 1$ opioid agonist, DPDPE, but not the $\delta 2$ agonist, deltorphin-II. Psychopharmacology. 2000; 152: 200-207.

114.Schalla MA, Stengel A. Activity based anorexia as an animal model for anorexia nervosa-a systematic review. Front Nutr. 2019; 6: 69.

115.Root TL, Pisetsky EM, Thornton L, Lichtenstein P, Pedersen NL, Bulik CM. Patterns of comorbidity of eating disorders and substance use in Swedish females. Psychol Med. 2010; 40: 105-115.

116.C Barbarich-Marsteller N, W Foltin R, Timothy Walsh B. Does anorexia nervosa resemble an addiction? Curr Drug Abuse Rev. 2011; 4: 197-200.

117.Baker JH, Mitchell KS, Neale MC, Kendler KS. Eating disorder symptomatology and substance use disorders: Prevalence and shared risk in a population based twin sample. Int J Eat Disord. 2010; 43: 648-658.

118. Bogenschutz MP, Forcehimes AA. Development of a psychotherapeutic model for psilocybinassisted treatment of alcoholism. J Humanist Psychol. 2017; 57: 389-414.

119. Bogenschutz MP, Forcehimes AA, Pommy JA, Wilcox CE, Barbosa PCR, Strassman RJ. Psilocybinassisted treatment for alcohol dependence: A proof-of-concept study. J Psychopharmacol. 2015; 29: 289-299.

120.Johnson MW, Garcia-Romeu A, Cosimano MP, Griffiths RR. Pilot study of the 5-HT2AR agonist psilocybin in the treatment of tobacco addiction. J Psychopharmacol. 2014; 28: 983-992. 
121.Numata N, Nakagawa A, Yoshioka K, Isomura K, Matsuzawa D, Setsu R, et al. Associations between autism spectrum disorder and eating disorders with and without self-induced vomiting: An empirical study. J Eat Disord. 2021; 9: 1-9.

122.Tchanturia K, Smith E, Weineck F, Fidanboylu E, Kern N, Treasure J, et al. Exploring autistic traits in anorexia: A clinical study. Mol Autism. 2013; 4: 1-8.

123. Mollinedo-Gajate I, Song C, Sintes-Rodriguez M, Whelan T, Soula A, Selimbeyoglu A, et al. Psilocybin rescues sociability deficits in an animal model of autism. bioRxiv. 2020. doi: 10.1101/2020.09.09.289348

124.Bender L, Cobrinik L, Faretra G, Sankar DV. The treatment of childhood schizophrenia with LSD and UML. Recent Adv Biol Psychiatry. 1961; 4: 170-179.

125.Sigafoos J, Green VA, Edrisinha C, Lancioni GE. Flashback to the 1960s: LSD in the treatment of autism. Dev Neurorehabil. 2007; 10: 75-81.

126.Galvão-Coelho NL, Marx W, Gonzalez M, Sinclair J, de Manincor M, Perkins D, et al. Classic serotonergic psychedelics for mood and depressive symptoms: A meta-analysis of mood disorder patients and healthy participants. Psychopharmacology. 2021; 238: 341-354.

127.Sherin JE, Nemeroff CB. Post-traumatic stress disorder: The neurobiological impact of psychological trauma. Dialogues Clin Neurosci. 2011; 13: 263-278.

128. Yohn CN, Gergues MM, Samuels BA. The role of 5-HT receptors in depression. Mol Brain. 2017; 10: 1-12.

129.Frokjaer VG, Mortensen EL, Nielsen FÅ, Haugbol S, Pinborg LH, Adams KH, et al. Frontolimbic serotonin $2 A$ receptor binding in healthy subjects is associated with personality risk factors for affective disorder. Biol Psychiatry. 2008; 63: 569-576.

130.Pandey GN, Dwivedi Y, Rizavi HS, Ren X, Pandey SC, Pesold C, et al. Higher expression of serotonin $5-\mathrm{HT} 2 \mathrm{~A}$ receptors in the postmortem brains of teenage suicide victims. Am J Psychiatry. 2002; 159: 419-429.

131.Riva G. Neurobiology of anorexia nervosa: Serotonin dysfunctions link self-starvation with body image disturbances through an impaired body memory. Front Hum Neurosci. 2016; 10: 600.

132. Kim K, Che T, Panova O, DiBerto JF, Lyu J, Krumm BE, et al. Structure of a hallucinogen-activated gq-coupled 5-ht2a serotonin receptor. Cell. 2020; 182: 1574-1588.

133. Poulie CB, Jensen AA, Halberstadt AL, Kristensen JL. Dark classics in chemical neuroscience: NBOMes. ACS Chem Neurosci. 2019; 11: 3860-3869.

134.López-Giménez JF, González-Maeso J. Hallucinogens and serotonin 5-HT2A receptor-mediated signaling pathways. Curr Top Behav Neurosci. 2018; 36: 45-73.

135.Dunlap LE, Azinfar A, Ly C, Cameron LP, Viswanathan J, Tombari RJ, et al. Identification of psychoplastogenic N,N-dimethylaminoisotryptamine (isoDMT) analogues through structureactivity relationship studies. J Med Chem. 2020; 63: 1142-1155.

136. Vollenweider FX. Brain mechanisms of hallucinogens and entactogens. Dialogues Clin Neurosci. 2001; 3: 265.

137. Kometer M, Schmidt A, Jäncke L, Vollenweider FX. Activation of serotonin 2A receptors underlies the psilocybin-induced effects on $\alpha$ oscillations, N170 visual-evoked potentials, and visual hallucinations. J Neurosci. 2013; 33: 10544-10551.

138. Vollenweider FX, Preller KH. Psychedelic drugs: Neurobiology and potential for treatment of psychiatric disorders. Nat Rev Neurosci. 2020; 21: 611-624. 
139.Preller KH, Vollenweider FX. Phenomenology, structure, and dynamic of psychedelic states. Curr Top Behav Neurosci. 2018; 36: 221-256.

140. Rolland B, Jardri R, Amad A, Thomas P, Cottencin O, Bordet R. Pharmacology of hallucinations: Several mechanisms for one single symptom? BioMed Res Int. 2014; 2014: 307106.

141.Madsen MK, Fisher PM, Burmester D, Dyssegaard A, Stenbæk DS, Kristiansen S, et al. Psychedelic effects of psilocybin correlate with serotonin $2 A$ receptor occupancy and plasma psilocin levels. Neuropsychopharmacology. 2019; 44: 1328-1334.

142. Walitza S, Wewetzer C, Warnke A, Gerlach M, Geller F, Gerber G, et al. 5-HT 2A promoter polymorphism-1438G/A in children and adolescents with obsessive-compulsive disorders. Mol Psychiatry. 2002; 7: 1054-1057.

143.Choi MJ, Lee HJ, Lee HJ, Ham BJ, Cha JH, Ryu SH, et al. Association between major depressive disorder and the-1438A/G polymorphism of the serotonin 2A receptor gene. Neuropsychobiology. 2004; 49: 38-41.

144.Ricca V, Nacmias B, Cellini E, Di Bernardo M, Rotella CM, Sorbi S. 5-HT2A receptor gene polymorphism and eating disorders. Neurosci Lett. 2002; 323: 105-108.

145.Eison AS, Mullins UL. Regulation of central 5-HT2A receptors: A review of in vivo studies. Behav Brain Res. 1995; 73: 177-181.

146. Kaye WH, Frank GK, Bailer UF, Henry SE, Meltzer CC, Price JC, et al. Serotonin alterations in anorexia and bulimia nervosa: New insights from imaging studies. Physiol Behav. 2005; 85: 7381.

147.Bailer UF, Kaye WH. Serotonin: Imaging findings in eating disorders. Curr Top Behav Neurosci. 2011: 6: 59-79.

148. Voigt JP, Fink H. Serotonin controlling feeding and satiety. Behav Brain Res. 2015; 277: 14-31.

149.Carhart-Harris RL, Nutt DJ. Serotonin and brain function: A tale of two receptors. J Psychopharmacol. 2017; 31: 1091-1120.

150.Carhart-Harris RL, Leech R, Hellyer PJ, Shanahan M, Feilding A, Tagliazucchi E, et al. The entropic brain: A theory of conscious states informed by neuroimaging research with psychedelic drugs. Front Hum Neurosci. 2014; 8: 20.

151.Carhart-Harris RL, Erritzoe D, Williams T, Stone JM, Reed L, Colasanti A, et al. Neural correlates of the psychedelic state as determined by fMRI studies with psilocybin. Proc Natl Acad Sci. 2012; 109: 2138-2143.

152.Rucker JJ, Iliff J, Nutt DJ. Psychiatry \& the psychedelic drugs. Past, present \& future. Neuropharmacology. 2018; 142: 200-218.

153.Dajani DR, Uddin LQ. Demystifying cognitive flexibility: Implications for clinical and developmental neuroscience. Trends Neurosci. 2015; 38: 571-578.

154. Roberts ME, Tchanturia K, Stahl D, Southgate L, Treasure J. A systematic review and metaanalysis of set-shifting ability in eating disorders. Psychol Med. 2007; 37: 1075-1084.

155.Roberts ME, Tchanturia K, Treasure JL. Exploring the neurocognitive signature of poor setshifting in anorexia and bulimia nervosa. J Psychiatr Res. 2010; 44: 964-970.

156.Tchanturia K, Davies H, Roberts M, Harrison A, Nakazato M, Schmidt U, et al. Poor cognitive flexibility in eating disorders: Examining the evidence using the Wisconsin Card Sorting Task. PLoS One. 2012; 7: e28331.

157. Friederich $\mathrm{H}$, Herzog W. Cognitive-behavioral flexibility in anorexia nervosa. Curr Top Behav Neurosci. 2011; 6: 111-123 
158. Treasure J, Schmidt U. The cognitive-interpersonal maintenance model of anorexia nervosa revisited: A summary of the evidence for cognitive, socio-emotional and interpersonal predisposing and perpetuating factors. J Eat Disord. 2013; 1: 1-10.

159.Foldi CJ, Liknaitzky P, Williams M, Oldfield BJ. Rethinking therapeutic strategies for anorexia nervosa: Insights from psychedelic medicine and animal models. Front Neurosci. 2020; 14: 1-8.

160.Garrison KA, Zeffiro TA, Scheinost D, Constable RT, Brewer JA. Meditation leads to reduced default mode network activity beyond an active task. Cogn Affect Behav Neurosci. 2015; 15: 712-720.

161.Lebedev AV, Lövdén M, Rosenthal G, Feilding A, Nutt DJ, Carhart-Harris RL. Finding the self by losing the self: Neural correlates of ego-dissolution under psilocybin. Hum Brain Mapp. 2015; 36: 3137-3153.

162.Carhart-Harris RL, Friston KJ. The default-mode, ego-functions and free-energy: A neurobiological account of Freudian ideas. Brain. 2010; 133: 1265-1283.

163. Carhart-Harris RL, Friston KJ. REBUS and the anarchic brain: Toward a unified model of the brain action of psychedelics. Pharmacol Rev. 2019; 71: 316-344.

164.Tagliazucchi E, Carhart-Harris R, Leech R, Nutt D, Chialvo DR. Enhanced repertoire of brain dynamical states during the psychedelic experience. Hum Brain Mapp. 2014; 35: 5442-5456.

165. Watts R, Luoma JB. The use of the psychological flexibility model to support psychedelic assisted therapy. J Contextual Behav Sci. 2020; 15: 92-102.

166.Barrett FS, Doss MK, Sepeda ND, Pekar JJ, Griffiths RR. Emotions and brain function are altered up to one month after a single high dose of psilocybin. Sci Rep. 2020; 10: 1-14.

167.Davis AK, Barrett FS, Griffiths RR. Psychological flexibility mediates the relations between acute psychedelic effects and subjective decreases in depression and anxiety. J Contextual Behav Sci. 2020; 15: 39-45.

168.Duriez P, Kaya Lefèvre H, Di Lodovico L, Viltart O, Gorwood P. Increased cognitive flexibility mediates the improvement of eating disorders symptoms, depressive symptoms and level of daily life functioning in patients with anorexia nervosa treated in specialised centres. Eur Eat Disord Rev. 2021; 29: 600-610.

169.Ghitza UE, Zhai H, Wu P, Airavaara M, Shaham Y, Lu L. Role of BDNF and GDNF in drug reward and relapse: A review. Neurosci Biobehav Rev. 2010; 35: 157-171.

170.Monteleone P, Fabrazzo M, Martiadis V, Serritella C, Pannuto M, Maj M. Circulating brainderived neurotrophic factor is decreased in women with anorexia and bulimia nervosa but not in women with binge-eating disorder: Relationships. Psychol Med. 2005; 35: 897-905.

171.Bathina S, Das UN. Brain-derived neurotrophic factor and its clinical implications. Arch Med Sci. 2015; 11: 1164-1178.

172. Miranda M, Morici JF, Zanoni MB, Bekinschtein P. Brain-derived neurotrophic factor: A key molecule for memory in the healthy and the pathological brain. Front Cell Neurosci. 2019; 13: 363.

173.Meng F, Liu J, Dai J, Wu M, Wang W, Liu C, et al. Brain-derived neurotrophic factor in 5-HT neurons regulates susceptibility to depression-related behaviors induced by subchronic unpredictable stress. J Psychiatr Res. 2020; 126: 55-66. 
174.King JA, Frank GK, Thompson PM, Ehrlich S. Structural neuroimaging of anorexia nervosa: Future directions in the quest for mechanisms underlying dynamic alterations. Biol Psychiatry. 2018; 83: 224-234.

175. Monzon BM, Hay P, Foroughi N, Touyz S. White matter alterations in anorexia nervosa: A systematic review of diffusion tensor imaging studies. World J Psychiatry. 2016; 6: 177-186.

176.Zhang S, Wang W, Su X, Kemp GJ, Yang X, Su J, et al. Psychoradiological investigations of gray matter alterations in patients with anorexia nervosa. Transl Psychiatry. 2018; 8: 1-11.

177.Mercader JM, Ribasés M, Gratacòs M, González JR, Bayés M, De Cid R, et al. Altered brainderived neurotrophic factor blood levels and gene variability are associated with anorexia and bulimia. Genes Brain Behav. 2007; 6: 706-716.

178. Ribases M, Gratacos M, Armengol L, De Cid R, Badia A, Jimenez L, et al. Met66 in the brainderived neurotrophic factor (BDNF) precursor is associated with anorexia nervosa restrictive type. Mol Psychiatry. 2003; 8: 745-751.

179. Hashimoto K, Koizumi H, Nakazato M, Shimizu E, lyo M. Role of brain-derived neurotrophic factor in eating disorders: Recent findings and its pathophysiological implications. Prog Neuropsychopharmacol Biol Psychiatry. 2005; 29: 499-504.

180.Scherag S, Hebebrand J, Hinney A. Eating disorders: The current status of molecular genetic research. Eur Child Adolesc Psychiatry. 2010; 19: 211-226.

181.Suliman S, Hemmings SM, Seedat S. Brain-Derived Neurotrophic Factor (BDNF) protein levels in anxiety disorders: Systematic review and meta-regression analysis. Front Integr Neurosci. 2013; 7: 55.

182.Takebayashi M, Hisaoka K, Nishida A, Tsuchioka M, Miyoshi I, Kozuru T, et al. Decreased levels of whole blood glial cell line-derived neurotrophic factor (GDNF) in remitted patients with mood disorders. Int J Neuropsychopharmacol. 2006; 9: 607-612.

183.Park YM, Lee BH. Alterations in serum BDNF and GDNF levels after 12 weeks of antidepressant treatment in female outpatients with major depressive disorder. Psychiatry Investig. 2018; 15: 818-823.

184. Heberlein A, Muschler M, Wilhelm J, Frieling H, Lenz B, Gröschl M, et al. BDNF and GDNF serum levels in alcohol-dependent patients during withdrawal. Prog Neuropsychopharmacology Biol Psychiatry. 2010; 34: 1060-1064.

185.Idell RD, Florova G, Komissarov AA, Shetty S, Girard RB, Idell S. The fibrinolytic system: A new target for treatment of depression with psychedelics. Med Hypotheses. 2017; 100: 46-53.

186. Ly C, Greb AC, Cameron LP, Wong JM, Barragan EV, Wilson PC, et al. Psychedelics promote structural and functional neural plasticity. Cell Rep. 2018; 23: 3170-3182.

187. Raval NR, Johansen A, Donovan LL, Ros NF, Ozenne B, Hansen HD, et al. A single dose of psilocybin increases synaptic density and decreases 5-HT2A receptor density in the pig brain. Int J Mol Sci. 2021; 22: 835.

188.Johnson MW, Griffiths RR, Hendricks PS, Henningfield JE. The abuse potential of medical psilocybin according to the 8 factors of the Controlled Substances Act. Neuropharmacology. 2018; 142: 143-166.

189. Heal DJ, Gosden J, Smith SL. Evaluating the abuse potential of psychedelic drugs as part of the safety pharmacology assessment for medical use in humans. Neuropharmacology. 2018; 142: 89-115. 
190.Schenberg EE. Psychedelic-assisted psychotherapy: A paradigm shift in psychiatric research and development. Front Pharmacol. 2018; 9: 733.

191.Argento E, Strathdee SA, Tupper K, Braschel M, Wood E, Shannon K. Does psychedelic drug use reduce risk of suicidality? Evidence from a longitudinal community-based cohort of marginalised women in a Canadian setting. BMJ Open. 2017; 7: e016025.

192.Fadiman J. The psychedelic explorer's guide: Safe, therapeutic, and sacred journeys. Rochester: Park Street Press; 2011.

193.Polito V, Stevenson RJ. A systematic study of microdosing psychedelics. PLoS One. 2019; 14: e0211023.

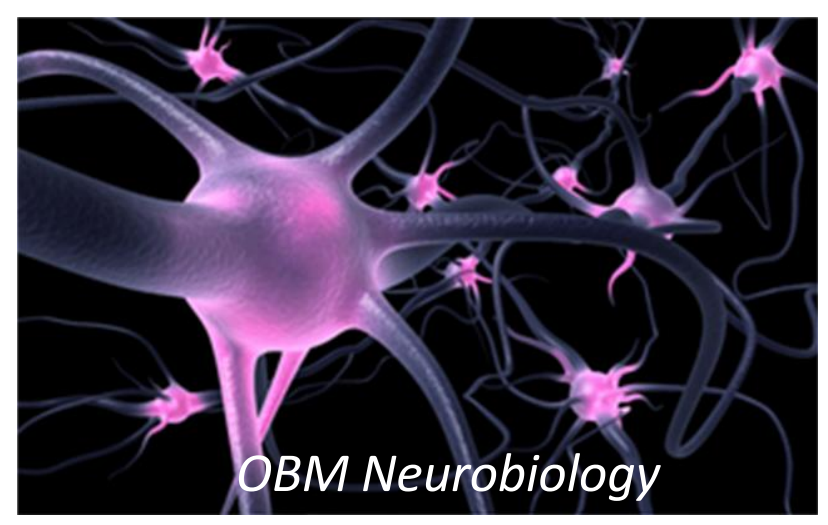

Enjoy OBM Neurobiology by:

1. Submitting a manuscript

2. Joining volunteer reviewer bank

3. Joining Editorial Board

4. Guest editing a special issue

For more details, please visit:

http://www.lidsen.com/journals/neurobiology 